\title{
TV White Space and LTE Network Optimization towards Energy Efficiency in Suburban and Rural Scenarios
}

\author{
Rodney Martinez Alonso, Student Member, IEEE, David Plets, Member, IEEE, Margot Deruyck, \\ Luc Martens, Member, IEEE, Glauco Guillen Nieto and Wout Joseph, Senior Member, IEEE
}

\begin{abstract}
The radio spectrum is a limited resource. Demand for wireless communication services is increasing exponentially, stressing the availability of radio spectrum to accommodate new services. TV White Space (TVWS) technologies allow a dynamic usage of the spectrum. These technologies provide wireless connectivity, in the channels of the Very High Frequency (VHF) and Ultra High Frequency (UHF) television broadcasting bands. In this paper, we investigate and compare the coverage range, network capacity, and network energy efficiency for TVWS technologies and LTE. We consider Ghent, Belgium and Boyeros, Havana, Cuba to evaluate a realistic outdoor suburban and rural area, respectively. The comparison shows that TVWS networks have an energy efficiency 9-12 times higher than LTE networks.
\end{abstract}

Index Terms-Wireless Networks, Network Planning, Coverage Prediction, TVWS, Energy Efficiency

\section{INTRODUCTION}

$\mathrm{W}$ IRELESS communication services are mainly provided under a fixed spectrum allocation. This spectrum allocation process is highly inefficient, leading to significant spectrum underutilization [1]. A radio spectrum usage survey in Virginia, United States, from $30 \mathrm{MHz}$ to $3 \mathrm{GHz}$, revealed that less than $20 \%$ is in use at any location and at any given time [1]. A survey in Brno, Czech Republic and Paris, France indicated even a lower spectrum usage in the range from $400 \mathrm{MHz}$ to $3 \mathrm{GHz}$ [2]. A study to account the percentage of TV White Spaces (TVWS) in 11 European countries revealed that $56 \%$ of UHF spectrum is not in use at any location and at any given time [3]. The estimated percentage of unused UHF spectrum in Belgium is $69 \%$ [3]. Although assigned by the local regulatory domain, only $44 \%$ of VHF and UHF spectrum is in use in Havana City and it will decrease to $12 \%$ after

Manuscript received April 6, 2017; revised June 19, 2017; accepted June 29, 2017; Date of current version July 3. R. Martinez Alonso is supported by LACETEL, and a doctoral grant from the Special Research Fund (BOF) of Ghent University, Belgium. M. Deruyck is a Post-Doctoral Fellow of the FWO-V (Research Foundation - Flanders, Belgium).

D. Plets, M. Deruyck, L. Martens and W. Joseph are with the INTEC Ghent University, Technologiepark-Zwijnaarde 15, 9052 Gent, Belgium (e-mail:\{david.plets,wout.joseph,margot.deruyck,luc1.martens\}@ ugent.be).

R. Martinez Alonso, is with LACETEL and INTEC Ghent University, Technologiepark-Zwijnaarde 15, 9052 Gent, Belgium (e-mail: rodney.martinezalonso@ugent.be).

G. Guillen Nieto is with the LACETEL, 34515 Rancho Boyeros Ave., Boyeros, 19200, Havana, Cuba (e-mail: glauco@enet.cu). analog broadcasting switch-off [4].

TVWS technologies dynamically allocate the required spectrum. The spectrum allocation is performed by means of cognitive radios with local spectrum sensing techniques and/or a geo-location database [5], [6]. Two main TVWS standards have been established based on the new dynamic spectrumsharing paradigm: IEEE 802.22 (latest update IEEE 802.22b) and IEEE 802.11af [7], [8], [9]. IEEE 802.22 was the first complete cognitive radio standard, including spectrum sensing techniques and geo-location capability with the provision to access a database that stores, by geographic location, the permissible frequencies and operating parameters [10]. An amendment in IEEE 802.11af enables geolocation database access to TVWS. The location algorithm allows the implementation of a closed-loop database. This database provides to Base Stations (BS) the white spaces availability, but also receives feedback from the geo-location of all network devices, their frequencies and emission footprints. By accessing and using this information, it is possible to coordinate and to make intelligent decisions about the most effective way to utilize the available spectrum [9], [11].

IEEE 802.11 p-2010 added more flexible mobile capability in Vehicular Ad-Hoc Networks (VANETs). This standard has been superseded by IEEE 802.11-2012 in which the content is now incorporated. In [12] the performance of VANET communications coexisting with DVB-T2 has been studied.

Several trials have been conducted worldwide to evaluate TVWS technologies [13]. In a trial with IEEE 802.22, a Bit Error Rate (BER) of $10^{-6}$ was reported at a distance of $6.3 \mathrm{~km}$ (one site measurement), for 3/4 64-QAM with an Equivalent Isotropic Radiated Power (EIRP) of $34.6 \mathrm{dBm}$, BS antenna height $20 \mathrm{~m}$, receiver antenna height of $12 \mathrm{~m}$ and receiver antenna gain of $7.65 \mathrm{dBi}$ [14]. A field trial for Line-Of-Sight (LOS) studied the bitrate versus coverage of a TVWS prototype in four outdoor measurement sites, considering different link margin and modulation schemes [15].

In [16], the authors analyzed the coverage for 802.11af BSs in a generic scenario, for different interference conditions and BS antenna heights. A bitrate performance comparison of TVWS technology and WiFi is presented in [17], considering the effect of interference and medium access congestion for Carrier Sense Multiple Access with Collision Avoidance 
(CSMA/CA) mode in IEEE 802.11af. Also [18] presented a throughput study of IEEE 802.11af for a rural area, considering the population density as reference. Several studies have investigated the white space channel availability for different interference considerations, protection margins and occupancy thresholds [3], [19], [20].

The power consumption models and energy efficiency for Long-Term Evolution (LTE) networks have been widely studied (i.e. [21], [22], [23], [24], [25]). For TVWS these parameters have not been properly investigated. A power consumption measurement for two different TVWS hardware is reported in [26], but neither power consumption model, energy efficiency nor network optimization is investigated.

In this paper we compare the coverage, performance and energy efficiency of TVWS technologies and LTE, in a suburban and a rural scenario, for the first time according to the authors' knowledge. A network optimization towards reduced power consumption is performed. We consider realistic user and traffic densities provided by local network operators. A novel power consumption model for TVWS technologies is proposed.

The outline of this paper is as follows. In Section II we describe the suburban and rural scenarios, the technology link budgets, the power consumption models, the energy efficiency metric, and the optimization algorithm. In Section III, we present the network simulation results for the proposed scenarios. Conclusions are presented in Section IV.

\section{METHOD}

First, we define the characteristics of each scenario and the link budget for each technology. The maximum coverage range and minimum required number of BS are estimated. Finally, an optimized network design towards minimum power consumption for TVWS and LTE is performed.

\section{A. Evaluation Scenarios}

We consider Ghent City, Belgium and Boyeros municipality outskirts in Havana, Cuba for the evaluation of a realistic suburban and rural area, respectively. Fig. 1a shows the target area $\left(68 \mathrm{~km}^{2}\right)$ that needs to be covered in Ghent City. Fig. 1b shows the target area $\left(169 \mathrm{~km}^{2}\right)$ that needs to be covered in Boyeros municipality. This area also includes some small towns at the outskirts of Havana City with dispersed population.

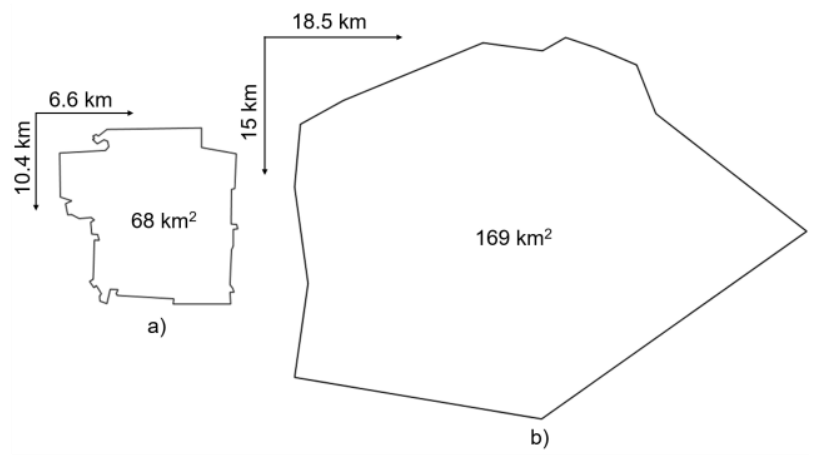

Fig. 1. The area to be covered, a) Ghent City (Suburban), b) Boyeros municipality - Havana outskirts (Rural).
We consider a wireless network setup based on a fixed outdoor over-roof antenna configuration. The end-point connection at the user's home is provided by a transceiver to an Ethernet or WiFi network. Fig. 2 shows the initial considered configuration.

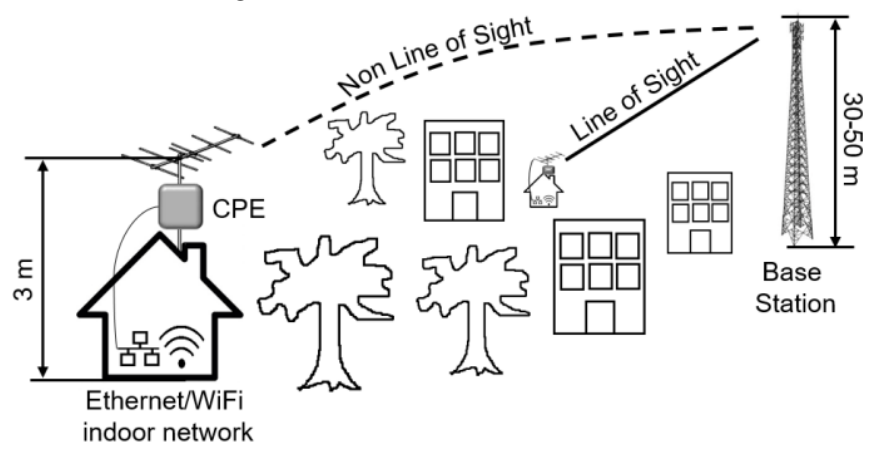

Fig. 2. Configuration for evaluation of TVWS and LTE technologies.

The wireless network design is based on a requirement of $90 \%$ of the locations covered at the edge of the coverage area during $99 \%$ of the time. The network must be able to handle up to 224 simultaneous connections in the suburban area and 135 simultaneous connections in the rural area. Some users require $64 \mathrm{kbps}$ (voice users, approximately $9 \%$ of total users) and others 1 Mbps (data users, approximately $91 \%$ of total users) [27]. The network planning is usually done for the peak traffic periods. Both user and traffic densities are based on real statistical data provided by the local operators for the peak network traffic to consider the worst case scenario.

The users are distributed uniformly and pseudo-randomly over the whole area. As consequence, each pixel in the map has the same probability to receive a user, with 0.09 probability of voice users and 0.91 of data users. The bitrate distribution is a probability mass function where the bitrate assignment can be considered as a discrete random variable defined by the sample space (discrete set of all possible outcomes, i.e. $64 \mathrm{kbps}$ or $1 \mathrm{Mbps}$ ).

In both suburban and rural scenarios, the antenna configuration is Single-Input Single-Output (SISO) with an omnidirectional radiation pattern. Therefore, the BS coverage area is represented by a circle with center in the BS location coordinates. LTE, IEEE 802.22b and IEEE 802.11af provide support for Multi-Input Multi-Output (MIMO) up to $4 \times 4$, although it is not widely industrialized yet [28], [8], [9]. The highest Modulation and Coding Schemes (MCS) for IEEE 802.22b (256-QAM schemes) are not implemented on commercial available hardware either. The influence of a MIMO 4x4 configuration will be evaluated for both scenarios (considering future hardware availability).

\section{B. Link Budgets and Propagation Models}

To estimate the range of each BS, the maximum allowable path loss $\mathrm{PL}_{\max }[\mathrm{dB}]$ for an acceptable BER performance has to be determined [21], [29]. To this aim, a link budget is defined according to the technology specifications and the scenario characteristics [29]. Table I lists the link budget parameters for each technology, in both scenarios. 
TABLE I

LINK BUDGET PARAMETERS (SUBURBAN/RURAL AREA)

\begin{tabular}{|c|c|c|c|c|c|}
\hline Parameter & 802.22 & 802.22b & 802.11af & LTE & Unit \\
\hline $\begin{array}{l}\text { Radiated } \\
\text { Power } \\
\end{array}$ & 36 & 36 & 36 & 36 & $\mathrm{dBm}$ \\
\hline Frequency & $602 / 605$ & $602 / 605$ & $602 / 605$ & 821 & $\mathrm{MHz}$ \\
\hline Bandwidth & $8 / 6$ & $8 / 6$ & $8 / 6$ & $10 / 5$ & $\mathrm{MHz}$ \\
\hline $\begin{array}{l}\text { Total } \\
\text { Subcarriers }\end{array}$ & 2048 & 1024 & 144 & $1024 / 512$ & - \\
\hline $\begin{array}{l}\text { Used } \\
\text { Subcarriers }\end{array}$ & 1680 & 832 & 114 & $601 / 301$ & - \\
\hline $\begin{array}{l}\text { Frequency } \\
\text { Sampling } \\
\text { Factor }\end{array}$ & 1.142 & 0.9325 & 1.142 & 1.536 & - \\
\hline $\begin{array}{l}\text { BS } \\
\text { Antenna } \\
\text { Height }\end{array}$ & $50 / 30$ & $50 / 30$ & $50 / 30$ & $50 / 30$ & $\mathrm{~m}$ \\
\hline $\begin{array}{l}\text { Cell } \\
\text { Interference } \\
\text { Margin }\end{array}$ & 0 & 0 & 0 & 2 & $\mathrm{~dB}$ \\
\hline MIMO Gain & - & 12 & 12 & 12 & $\mathrm{~dB}$ \\
\hline $\begin{array}{l}\text { Receiver } \\
\text { Antenna } \\
\text { Height }\end{array}$ & 3 & 3 & 3 & 3 & $\mathrm{~m}$ \\
\hline $\begin{array}{l}\text { Receiver } \\
\text { Antenna } \\
\text { Gain } \\
\end{array}$ & 11.5 & 11.5 & 11.5 & 11.5 & $\mathrm{~dB}$ \\
\hline $\begin{array}{l}\text { Receiver } \\
\text { Feeder } \\
\text { Losses } \\
\end{array}$ & 0.04 & 0.04 & 0.04 & 0.04 & $\mathrm{~dB}$ \\
\hline Noise Figure & 4 & 4 & 4 & 7 & $\mathrm{~dB}$ \\
\hline $\begin{array}{l}\text { Shadow } \\
\text { Margin }\end{array}$ & $7.91 / 5.5$ & $7.91 / 5.5$ & $7.91 / 5.5$ & $7.91 / 5.5$ & $\mathrm{~dB}$ \\
\hline Fade Margin & $7.37 / 4$ & $7.37 / 4$ & $7.37 / 4$ & $7.37 / 4$ & $\mathrm{~dB}$ \\
\hline $\begin{array}{l}\text { Receiver } \\
\text { Signal to } \\
\text { Noise Ratio } \\
\text { (SNR) }\end{array}$ & $\begin{array}{r}4.3 \\
10.2 \\
12.4 \\
18.3 \\
19.7\end{array}$ & $\begin{array}{r}4.3 \\
10.2 \\
12.4 \\
18.3 \\
19.7 \\
26.9 \\
28.2 \\
\end{array}$ & $\begin{array}{r}3.8 \\
8.0 \\
15.1 \\
25.2 \\
30.4\end{array}$ & $\begin{array}{r}3.0 \\
10.5 \\
14.0 \\
22.0 \\
29.4\end{array}$ & $\mathrm{~dB}$ \\
\hline \multirow{4}{*}{ Bitrate } & & @ $8 \mathrm{MHz}$ & & @ $10 \mathrm{MHz}$ & \multirow{4}{*}{ Mbps } \\
\hline & $\begin{array}{r}6.0 \\
12.0 \\
16.1 \\
24.1 \\
27.2\end{array}$ & $\begin{array}{r}6.0 \\
12.0 \\
16.1 \\
24.1 \\
27.2 \\
32.2 \\
42.3 \\
\end{array}$ & $\begin{array}{r}2.4 \\
7.2 \\
14.4 \\
24.0 \\
32.0\end{array}$ & $\begin{array}{r}4.32 \\
6.3 \\
16.8 \\
25.2 \\
38.7\end{array}$ & \\
\hline & & @ $6 \mathrm{MHz}$ & & @ $5 \mathrm{MHz}$ & \\
\hline & $\begin{array}{r}4.5 \\
9.0 \\
12.1 \\
18.1 \\
20.4\end{array}$ & $\begin{array}{r}4.5 \\
9.0 \\
12.1 \\
18.1 \\
20.4 \\
24.2 \\
31.7\end{array}$ & $\begin{array}{r}1.8 \\
5.4 \\
10.8 \\
18.0 \\
24.0\end{array}$ & $\begin{array}{r}4.2 \\
5.7 \\
8.5 \\
11.3 \\
16.9\end{array}$ & \\
\hline
\end{tabular}

Main link budget differences from one scenario to another one arise in the parameters related to the propagation environment (i.e. shadowing and fading margin) and the regulatory domain (i.e. bandwidth, frequency). The radiated power (EIRP) corresponds to the maximum allowable [8]. The bandwidth corresponds to the channel distribution in each region [30], [31].

The OFDM parameters are retrieved from the standards [7], [8], [9], [32]. Note that the frequency sampling factor is the ratio of the sampling frequency and the channel bandwidth. The SNR is recommended for IEEE 802.22 and IEEE $802.22 \mathrm{~b}$
[7], [8] and guarantees a Bit Error Rate better than $10^{-7}$, considering the co-channel interference of a DVB-T2 TV broadcasting network [33]. For LTE and IEEE 802.11af, we consider the SNR reported in private interviews with manufacturers. Other parameters such as antenna heights, antenna gains and feeder losses are also typical implementation values, as reported by manufacturers.

The cell interference margin for TVWS technologies is $0 \mathrm{~dB}$. We consider TVWS operation in non-interfering channels only ( 25 non-interfering TVWS channels available in Ghent [34]) and the strictest spectrum-sensing modes defined in the standards. The channel allocation is based on the detection of the wireless beacon (IEEE 802.22.1). It means that a channel will be considered occupied if a wireless beacon frame, with a level equal or higher than $-116 \mathrm{dBm}$ is detected. For a complementary protection from/to the primary TV broadcasting services, we assume a geo-location database with a similar constraint.

Even under the considered constraints, the coexistence of joint IEEE 802.22 and IEEE 802.11af operating in the same region is not solved yet. In such condition, the probability of IEEE 802.22 users to get access to the spectrum resources is higher [35]. For a fair comparison, we assume that a single TVWS technology is deployed in the target area at the same time. State-of-the-art TVWS receivers have a noise figure from 3 to $4 \mathrm{~dB}$ [36]. To evaluate the worst case scenario, all calculations are based on a noise figure of $4 \mathrm{~dB}$. For LTE, the macrocell propagation model proposed by ETSI (European Telecommunications Standards Institute) considers a Customer-Premises Equipment (CPE) noise figure of $9 \mathrm{~dB}$ [37]. The noise figure of current fixed outdoor LTE receivers (in the frequency of interest) varies from $4 \mathrm{~dB}$ to $8 \mathrm{~dB}$. We assume a noise figure of $7 \mathrm{~dB}$ for LTE fixed outdoor CPE (see Table I).

In suburban Ghent, we consider a shadow margin of $7.91 \mathrm{~dB}$, for $90 \%$ of locations covered at a certain distance from the transmitter [38] and a fading margin of $7.37 \mathrm{~dB}$ for 99\% availability [39]. Boyeros municipality in Havana outskirts, is a rural area with a low foliage density. To achieve the same coverage and availability percentages, we consider a shadow margin of $5.5 \mathrm{~dB}$ and a fading margin of $4 \mathrm{~dB}$ [39]. Note that over-roof reception network planning does not require accounting for building penetration losses [40].

Different path loss models have been studied to estimate the path loss in the UHF band. For instance, the ITU-R P.1546 presents a method for point-to-area radio propagation predictions for terrestrial services and was originally derived from measurements performed for VHF and UHF broadcasting [41], ITU-R P.1812 for path-specific propagation prediction method for point-to-area terrestrial services at VHF and UHF bands [42] and Okumura-Hata model [43]. For Ghent City an experimental path loss model based on extensive measurement campaign is described in [38]. For Boyeros (rural scenario) an experimental path loss model is not available.

Fig. 3 shows a comparison among Okumura-Hata, ITU-R P.1546 and Ghent Model. Note that ITU-R P.1812 requires a digital terrain database or $3 \mathrm{D}$ environmental map, 
which is not available for the rural scenario [42].

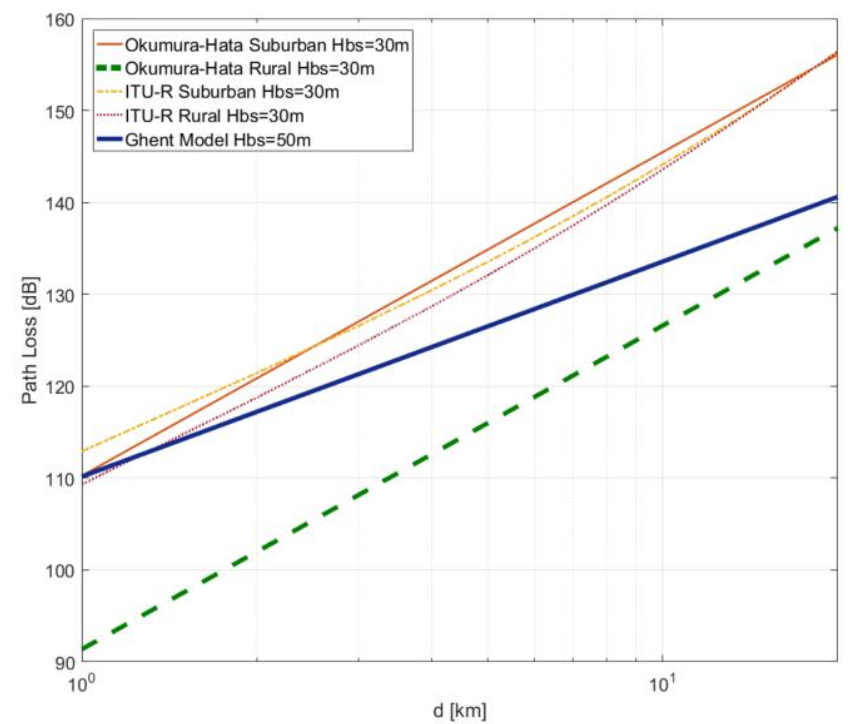

Fig. 3. Path loss models.

The ITU-R P.1546 model and Okumura-Hata model for suburban scenarios retrieve similar results. Nevertheless, for a rural scenario there is a higher difference between both models. Considering the same conditions of the Ghent model measurement campaign [38], the ITU-R P.1546 even with the rural correction factors overestimates the path loss for Ghent City. The rural consideration of Okumura-Hata model is a quasi-open area at the receiver location, which better fits with the topology at Havana outskirts. Therefore, for the rural scenario the coverage prediction is based on Okumura-Hata path loss model.

\section{Minimum required number of Base Stations}

The minimum required number of BS depends on both the area to be covered and the served traffic. To cover a target area $A_{T}\left(\mathrm{~km}^{2}\right)$, the minimum required number of BS $\left(\mathrm{N}_{\mathrm{BSa}}\right)$ can be defined as a function of the maximal BS coverage range $R(\mathrm{~km})$, with $[\cdot]$ the ceil function:

$$
N_{B S a}=\left\lceil\frac{A_{T}}{\pi \cdot R^{2}}\right\rceil
$$

Taking into consideration the total traffic requirement $T$ (Mbps) within the area $A_{T}$ (i.e. the sum of the individual traffic requirements of all simultaneous users), the minimum required number of $\mathrm{BS}\left(\mathrm{N}_{\mathrm{BSt}}\right)$ as a function of the bitrate served by a single $\mathrm{BS}, B_{B S}$ (Mbps), can be defined by the following equation:

$$
N_{B S t}=\left\lceil\frac{T}{B_{B S}}\right\rceil
$$

The actually required number of BS ( $\left.\mathrm{N}_{\mathrm{BS} \text { _total }}\right)$ depends also on the target area topology, the distribution of possible BS locations and the network optimization algorithm. Equation 3 provides a minimum to the required number of BS.

$$
N_{B S_{\text {_total }}} \geq \max \left(N_{B S a}, N_{B S t}\right)
$$

\section{Energy Efficiency Metric}

A metric to account for the energy efficiency of a single BS is defined in [22]. An extension of this metric, to account for the energy efficiency of the whole network configuration is defined in [44]. The average network energy efficiency $E E_{n}\left(\mathrm{~km}^{2} \cdot \mathrm{Mbps} / \mathrm{W}\right)$ for $t$ different user distributions and a certain coverage percentage of users $c_{i}$ can be defined as follows:

$$
E E_{n}=\frac{1}{t} \cdot \sum_{i=1}^{t} \frac{c_{i} \cdot A_{T} \cdot U \cdot \sum_{j=1}^{m} B_{i j}}{\sum_{j=1}^{m} P_{B S_{i j}}}
$$

where $A_{T}$ is target area, $U$ is the number of users in the target area, $B_{i j}$ represents the total bitrate provided by BS $j$ to the users population $i, m$ is the total number of $\mathrm{BS}$ and $P_{B S i j}$ represents the power consumption of the $B S_{i j}$.

The power consumption of LTE BS has been studied in [22], [25], [24]. To account for the power consumption of each LTE BS we consider the model proposed in [22]. This model takes into account the radiated power, the amplifier efficiency and the radiation system efficiency. Fig. 4a shows the power consuming components of an LTE BS. We assume an optical backhaul power consumption of $32 \mathrm{~W}$ for LTE [45].

In Fig. 4b we propose a power consumption model for the TVWS BS. This model comprises three power-consuming components: the Radio Unit (RU), the Power Supply (Power over Ethernet (PoE)) and the Optical Backhaul.

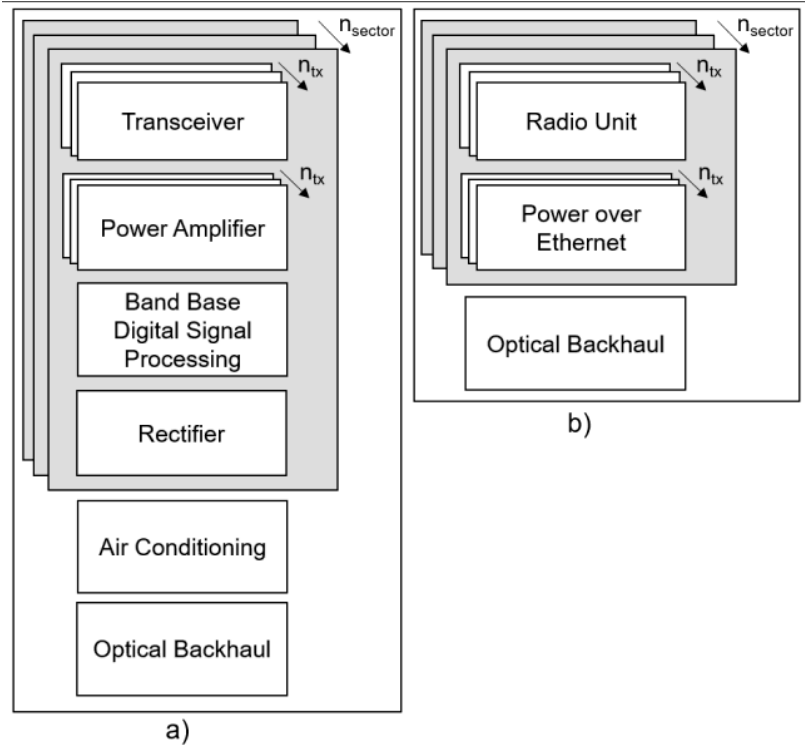

Fig. 4. Block diagram of power-consuming components a) LTE [22] b) TVWS. 
The total power consumption of a TVWS BS can be calculated as follows:

$$
P_{B S}=P_{b h}+P_{i d l e}+n_{s t} \cdot n_{t x} \cdot \alpha \cdot\left(\frac{P_{r}}{\eta_{r u}}+P_{P o E}\right)
$$

We consider the power consumption of the optical backhaul $P_{b h}$ to be constant and independent from the number of sectors and transmitters. The PoE power consumption $\left(P_{P o E}\right)$ and RU power consumption varies with the traffic load factor $\alpha$. We will consider $\alpha=1$ to investigate the maximal power consumption of the BS (worst-case scenario). For OFDM applications, the power amplifier of the RU should operate in the linear region. The relation between the transmitter output power and BS power consumption is nearly linear [25]. The power consumption of the RU can be correlated with the radiated power $P_{r}$ (for $n_{s t}$ sectors and $n_{t x}$ transmitters) by means of a linear function. The slope $\left(\eta_{r u}\right)$ of this function is the ratio of radiated per consumed power. For the maximum power of $1 \mathrm{~W}$ in the amplifier output (equivalent to a maximum radiated power $P_{r \max }=4 \mathrm{~W}$ ) the RU maximum power consumption $\left(P_{B S \max }\right)$ is approximately $28 \mathrm{~W}$ [26]. However, not all the consumed power can be correlated with the radiated power. The RU also has an idle power consumption $P_{\text {idle }}=6 \mathrm{~W}$ for $P_{r}=0 \mathrm{~W}$ [36]. Thus, $\eta_{r u}$ can be calculated as follows:

$$
\eta_{r u}=\frac{P_{r \max }}{P_{B S \max }-P_{\text {idle }}}=0.182
$$

Table II lists the power consumption values for a TVWS BS.

TABLE II

TVWS POWER MODEL PARAMETERS

\begin{tabular}{crc}
\hline \hline Parameter & Value & Unit \\
\hline $\mathrm{P}_{\mathrm{bh}}[45]$ & 32 & $\mathrm{~W}$ \\
$\mathrm{P}_{\mathrm{PoE}}[46]$ & 4 & $\mathrm{~W}$ \\
$\mathrm{P}_{\mathrm{idll}}[36]$ & 6 & $\mathrm{~W}$ \\
$\eta_{\mathrm{ru}}$ & 0.182 & - \\
\hline \hline
\end{tabular}

For a single transmitter and sector with $P_{r}=4 \mathrm{~W}$ and $\alpha=1$ the power consumption of a TVWS BS is as low as $64 \mathrm{~W}$. Digital Signal Processing (DSP) on TVWS BSs is generally implemented by a dedicated chipset (i.e. [36]). This is highly energy efficient [47] but, as a drawback, BSs are not upgradeable to support future standards or re-scale.

\section{E. Optimization algorithm}

The network planning is performed by GRAND (Green Radio and Access Network Design) optimization algorithm described in [27]. First, the network traffic is generated for 40 simulations (40 different spatial user distributions and user bitrate distributions). Fig. 5 shows a heuristic algorithm towards minimizing the network power consumption. The algorithm seeks to connect each user to the BS with the lowest path loss and lower BS powers in order to reduce the power consumption by reducing the radiated power. The heuristic will not be the absolute best solution, but a solution that solves the optimization problem in a reasonable time frame.

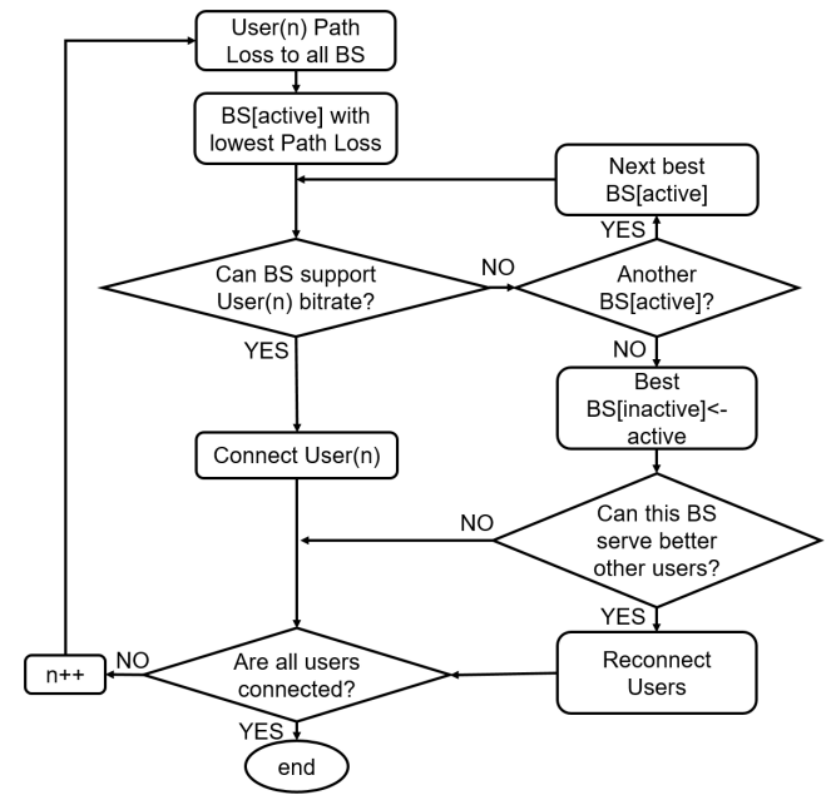

Fig. 5. Network optimization algorithm [27].

For each simulation, the software calculates the path loss between a user and all possible BSs. The algorithm first seeks to connect each user to the BS corresponding with the lowest path loss. A certain user is connected to a BS only if the BS is already active and still can support the bitrate demanded by the user. In this way, the algorithm tends to minimize the number of active BS. In case a BS can not support the current user the algorithm seeks for the next already active BS with lowest path loss. In case no active BS can be found, the algorithm will activate the most appropriate BS (lowest path loss) from the inactive ones. When a new BS is activated, the algorithm checks if users already connected can be switched in order to balance the network load. A certain user is only switched to another BS if the pass loss to the new BS is lower. The described algorithm is repeated until all users are evaluated. More details on the algorithm can be found in [27].

The progressive average for all simulations is calculated to validate a proper estimation of the percentage of users covered.

\section{RESULTS}

This section presents the results of the network simulations and optimizations for the considered scenarios.

\section{A. Maximum coverage for one Base Station}

Fig. 6 shows the BS bitrate versus coverage range for the suburban and rural area. For the maximum EIRP, IEEE 802.22b BS has a higher coverage range than LTE, IEEE 802.22 and IEEE 802.11af. The maximum coverage range for IEEE $802.22 \mathrm{~b}$ is equal to $7.0 \mathrm{~km}$ in the suburban scenario and $17.6 \mathrm{~km}$ in the rural scenario (MCS 1/2 QPSK). The LTE BS has the lowest coverage range: $3.2 \mathrm{~km}$ and $12.1 \mathrm{~km}(1 / 2 \mathrm{QPSK})$, in the suburban and rural area, respectively. The lower coverage is due to a $3 \mathrm{~dB}$ higher noise 
factor compared with TVWS technologies and 2 to $4 \mathrm{~dB}$ higher required SNR than IEEE 802.22b. The latest version IEEE $802.22 \mathrm{~b}$ achieves a 5 to $8 \%$ higher coverage range than IEEE 802.22 due to an improvement in the ratio of OFDM used from total subcarriers and a better sampling frequency factor. In comparison, IEEE 802.11 af achieves a 15 to $30 \%$ lower coverage because it requires a higher SNR (an average $6 \mathrm{~dB}$ higher).

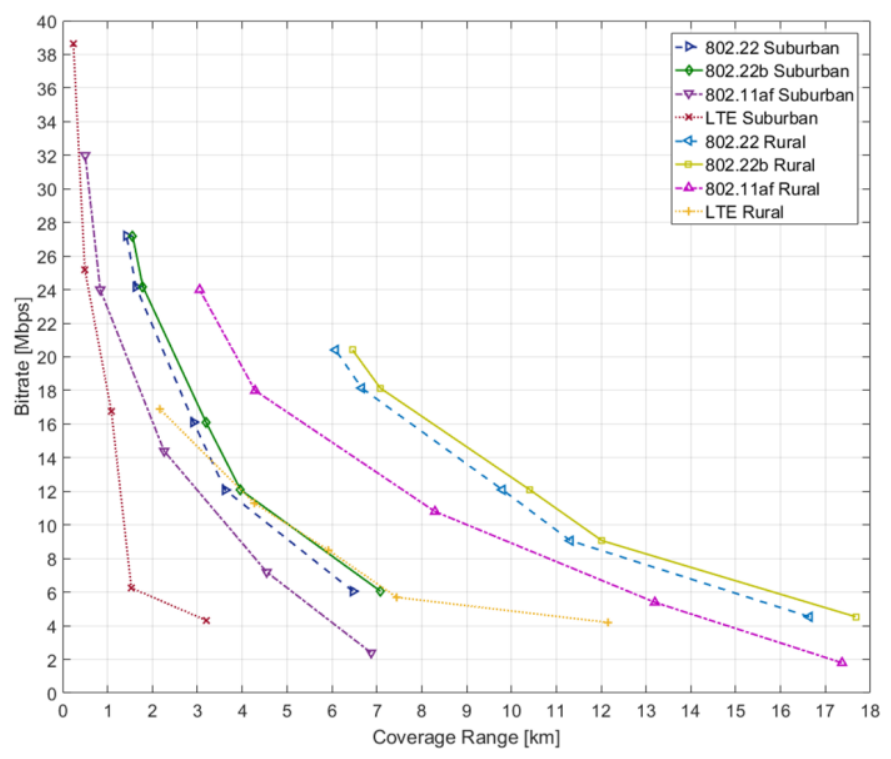

Fig. 6. BS comparison of bitrate versus coverage for the maximum EIRP.

\section{B. Network planning and optimization}

First, we simulate the network for the minimum required number of BS (see Equation 3). Fig. 7 and Fig. 8 show the minimum required number of BS in the suburban and rural scenario, respectively. These graphs represent the trade-off between coverage and capacity. For a higher bitrate (i.e. higher required SNR), the number of BS to satisfy a certain traffic $\left(\mathrm{N}_{\mathrm{BSt}}\right)$ decreases. A higher SNR has as consequence, a reduction in coverage and the number of $\mathrm{BS}$ to cover a certain area $\left(\mathrm{N}_{\mathrm{BSa}}\right)$ increases. IEEE 802.22 and IEEE $802.22 \mathrm{~b}$ have the lowest required number of BS. This is because it has a better coverage per provided bitrate unit in both scenarios (see Fig. 6).

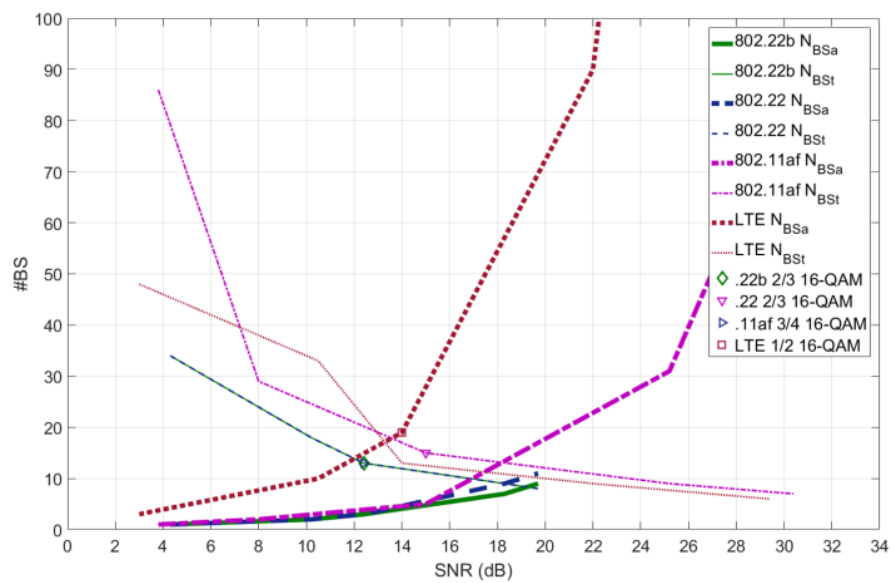

Fig. 7. Minimum required number of BS vs required SNR in the suburban scenario. The markers indicates the optimal MCSs.

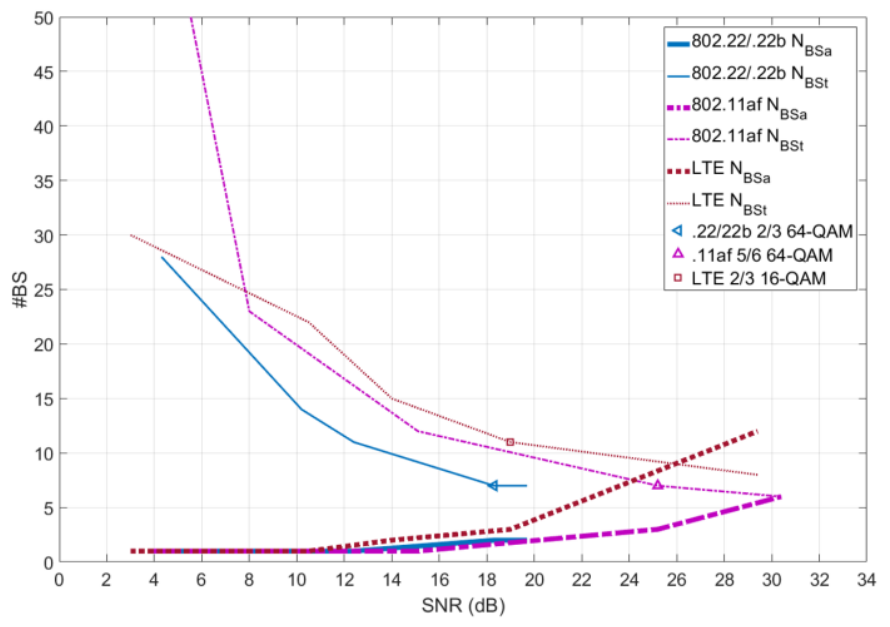

Fig. 8. Minimum required number of BS vs required SNR in the rural scenario. The markers indicates the optimal MCSs.

The minimum required number of BS locations in the rural area is lower for all the standards, due to a better propagation environment and lower traffic density.

In the suburban scenario, the lowest required number of BSs and highest percentage of users covered are achieved for the MCS 2/3 16-QAM for IEEE 802.22 and IEEE 802.22b, 3/4 16-QAM for IEEE 802.11af and 1/2 16-QAM for LTE (see markers in Fig. 7). Note that in the suburban scenario the MCS 2/3 16-QAM (IEEE 802.22 and IEEE 802.22b) does not has the lowest max $\left(\mathrm{N}_{\mathrm{BSa}}, \mathrm{N}_{\mathrm{BSt}}\right)$. Nevertheless, the best network planning in terms of energy efficiency is achieved when the network is designed to guarantee that all users can be connected with this MCS. This is because of for MCS with a similar minimum number of required $\mathrm{BS}$, the area constraint $\left(\mathrm{N}_{\mathrm{BS}}\right)$ prevails due to the deviation caused by the area geometry and BS location distribution. In the rural scenario, the best trade-off is achieved for the MCS 2/3 64-QAM for IEEE 802.22 and IEEE 802.22b, 5/6 64-QAM for IEEE 802.11af and 2/3 16-QAM for LTE (see markers in Fig. 8).

Equation 3 provides a theoretical minimum $\mathrm{N}_{\mathrm{BS} \_ \text {total }}$ been required a higher number of BS. This is due to the area geometry and BS location influence. Therefore, the number of BS is increased until we reach a mean coverage higher than $95 \%$.

Fig. 9 shows the network coverage map for each technology in both scenarios for the most efficient MCSs in terms of energy efficiency. The optimal MCS yields the highest energy efficiency with the lowest number of BSs that allow to meeting both, the coverage and traffic demand. In the suburban scenario, the number of considered BS locations is 20 for IEEE 802.22 and 802.22 b, 21 for IEEE 802.11af and 36 for LTE. In the rural scenario, the number of considered BS locations is 10 for all TVWS technologies and 13 for LTE. Although the target area in the rural scenario is more than two times larger than the suburban scenario, the number of BS locations can be reduced around to half (keeping a similar percentage of coverage). This is because the rural environment has a lower path loss and lower traffic requirement. 
The mean percentage of users covered is $95 \%$ for LTE and higher than $96 \%$ for TVWS technologies in the suburban scenario. In the rural scenario the mean percentage of users covered is higher than $96 \%$ for IEEE 802.11 af and LTE, and higher than $99 \%$ for IEEE 802.22 and IEEE 802.22b. The deviation of the mean value of the percentage of users covered is lower than $0.5 \%$ over the considered simulations.
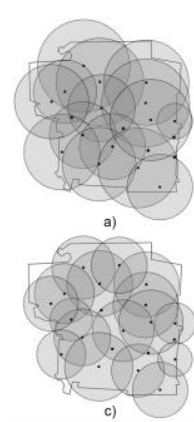

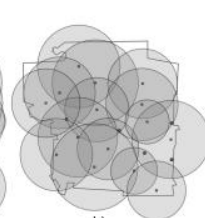

b)

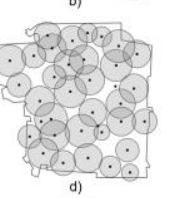

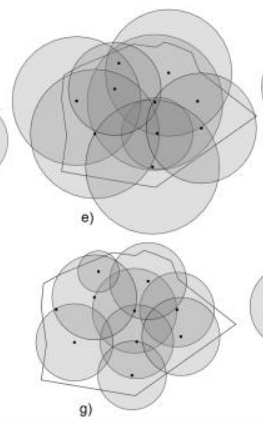

g)

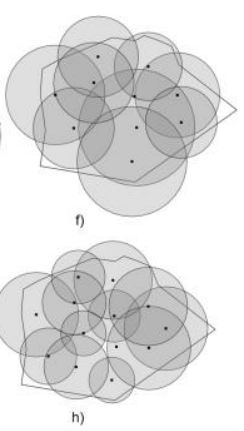

Fig. 9. Optimized networks (towards minimum power consumption) in Ghent area (suburban), for a) IEEE $802.22 b$, b) IEEE 802.22, c) IEEE 802.11af, d) LTE technology and Boyeros area (rural) for e) IEEE $802.22 \mathrm{~b}$, f) IEEE 802.22, g) IEEE 802.11af, h) LTE technology.

Fig. 10 shows the average network energy efficiency and its standard deviation for each technology. The best solution to cover the suburban area is IEEE $802.22 \mathrm{~b}$ with an average network energy efficiency of $2996.8 \mathrm{~km}^{2} \cdot \mathrm{Mbps} / \mathrm{W}$. Note that the energy efficiency difference between IEEE $802.22 \mathrm{~b}$ and IEEE 802.22 is lower than the standard deviation.

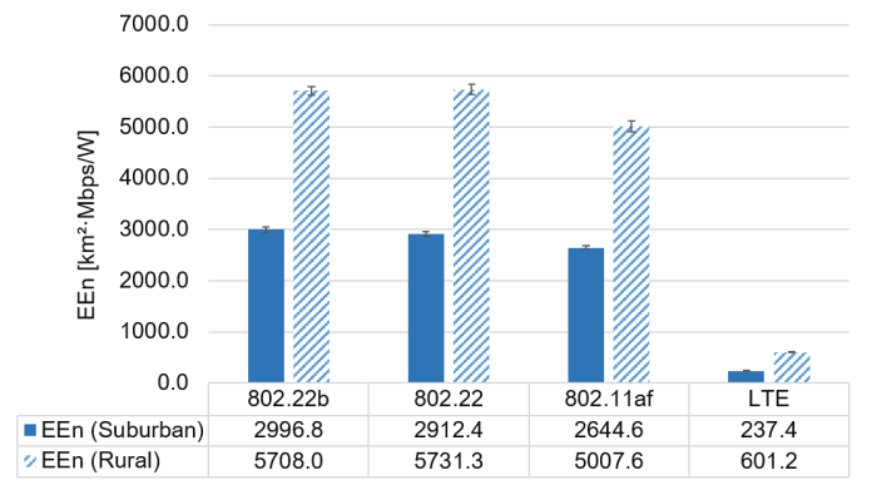

Fig. 10. Average network energy efficiency in the suburban and rural scenarios.

The LTE network has an energy efficiency more than 12 times lower. This is due to a lower coverage per provided bitrate unit (see Fig. 6) but also a higher network power consumption. The total power consumption for TVWS networks ranges from $1010 \mathrm{~W}$ (IEEE 802.22b) to $1044 \mathrm{~W}$ (IEEE 802.11af). The full LTE network has an average power consumption of $11883 \mathrm{~W}$.

The energy efficiency in the rural scenario is higher than the energy efficiency in the suburban scenario due to a better propagation environment and lower traffic density. This leads towards a lower number of BSs and lower network power consumption. The network power consumption for the TVWS networks ranges from $489 \mathrm{~W}$ (IEEE 802.22) to $521 \mathrm{~W}$ (IEEE 802.11af) and $4362 \mathrm{~W}$ for LTE.
The best solutions to cover the rural area are IEEE $802.22 \mathrm{~b}$ and IEEE 802.22 (difference lower than the standard deviation). This is because the slightly difference in coverage per bitrate provided (see Fig. 6) is not enough to compensate the deviation caused by the BS location distribution and area geometry.

\section{Influence of MIMO}

The diversity gain increases the coverage of each BS. As a consequence, the number of BSs can be reduced. In the suburban scenario with a MIMO $4 \times 4$ configuration the number of BSs can be reduced to 11 for TVWS technologies and 15 for LTE. The best trade-off between area covered and capacity is achieved for 3/4 64-QAM for IEEE $802.22 \mathrm{~b}$, 5/6 64-QAM for IEEE 802.11af and 1/2 16-QAM for LTE. In the rural scenario, the number of required BSs can be reduced to 5 for IEEE 802.22b, 8 for IEEE 802.11af and 10 for LTE.

Fig. 11 shows the average network energy efficiency for MIMO $4 \times 4$ compared with SISO configuration. In the suburban scenario, the energy efficiency of IEEE $802.22 \mathrm{~b}$ with a $4 \times 4$ MIMO configuration is slightly increased by $4 \%$ while for LTE by $47 \%$ (compared with SISO).

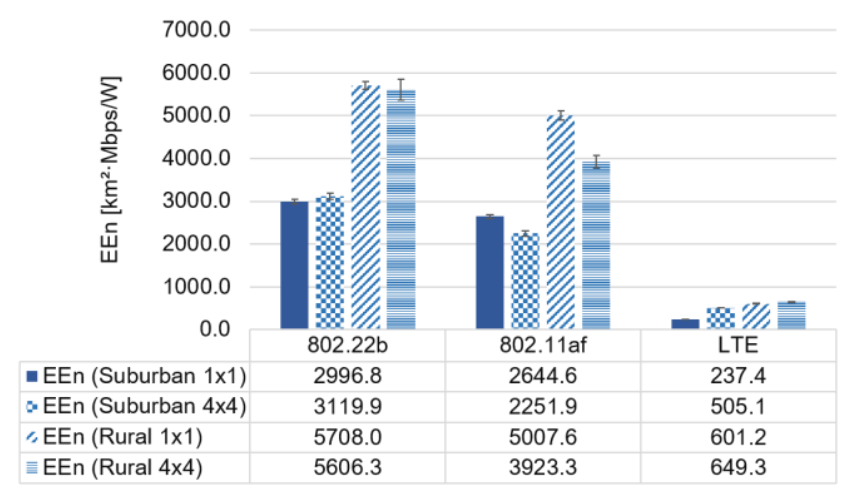

Fig. 11. Average network energy efficiency in the suburban and rural scenario. MIMO 4x4 versus SISO configuration.

For IEEE 802.11af the energy efficiency decreases approximately $15 \%$ when comparing with SISO. In the suburban scenario, four transmitting antennas significantly increases the network energy efficiency for LTE but not for TVWS. For LTE BSs, the transmitters consume less than $10 \%$ of the BS total consumed power. The coverage increase realized by the MIMO diversity gain, together with the reduction of BS sites, overcompensates the increase in the transmitters' power consumption. For TVWS BS the power consumption of the transmitters represents around $40 \%$ of the total consumed power. The increase in the power consumption of the transmitters is not always compensated.

For the rural scenario, the minimum required number of BS is always defined by the traffic constraint. Only 1 to $3 \mathrm{BS}$ are required to cover the whole area however these can not support the traffic demand. The usage of four transmitters leads towards a higher power consumption not compensated by the coverage increase. As consequence, for the rural scenario the energy efficiency slightly increases by $7 \%$ for LTE, remaining approximately the same for IEEE 802.22b (the difference is less than the standard deviation), while 
decreases more than $21 \%$ for IEEE 802.11af. Nevertheless, all the technologies have a better performance in the rural scenario, prevailing the better propagation conditions.

\section{CONCLUSION}

By using novel network planning software, we investigated the coverage, capacity and energy efficiency of TVWS networks, optimized towards reducing its power consumption, in realistic suburban and rural scenarios. For this aim, we proposed a model to determine the power consumption of TVWS networks. We also optimized and investigated an LTE network for a reference comparison. This comparison reveals that LTE has a lower energy efficiency in both suburban (approximately 12 times lower) and rural (approximately 9 times lower) scenario. IEEE 802.22b achieves the highest energy efficiency (12\% higher than IEEE 802.11af).

For TVWS technologies, the use of a MIMO $4 \times 4$ configuration allows reducing the number of BS locations but does not significantly increase the energy efficiency in the considered scenarios.

Future research will consist of planning energy efficient Internet of Things (IoT) wireless networks in TVWS band. A huge density of devices will have to be considered and coverage, capacity and density will play a key role.

\section{REFERENCES}

[1] Shared Spectrum Company, "General Survey of Radio Frequency Bands - $30 \mathrm{MHz}$ to $3 \mathrm{GHz}$," Vienna, Virginia, 2010.

[2] V. Valenta, R. Marsalek, G. Baudoin and M. Villegas, "Survey on Spectrum Utilization in Europe: Measurements, Analyses and Observations," 5th International ICST Conference on Cognitive Radio Oriented Wireless Networks and Communications, 2010.

[3] J. van de Beek, J. Riihijarvi and A. Achtzehn, "TV White Space in Europe," IEEE TRANSACTIONS ON MOBILE COMPUTING, vol. 11, no. 2, pp. 178-188, 2011.

[4] G. Guillen Nieto, "Digital TV: Oportunities and conectivity alternatives Radio Cognitive," in 4th International Digital TV Forum, Havana, 2016.

[5] M. Murroni and e. al., "IEEE 1900.6: spectrum sensing interfaces and data structures for dynamic spectrum access and other advanced radio communication systems standard: technical aspects and future outlook," IEEE Communications Magazine, vol. 49, no. 12, pp. 118-127, 2011.

[6] M. Fadda, M. Murroni, C. Perra and V. Popescu, "TV white spaces exploitation for multimedia signal distribution," Signal Process. Image Communication, vol. 27, no. 8, pp. 893-899, 2012.

[7] IEEE Computer Society, "IEEE 802.22. Part 22: Cognitive Wireless RAN Medium Access Control (MAC) and Physical Layer (PHY) specifications: Policies and procedures for operation," IEEE, New York, 2011.

[8] IEEE Computer Society, "IEEE 802.22b. Part 22: Cognitive Wireless RAN Medium Access Control (MAC) and Physical Layer (PHY) Specifications: Policies and Procedures for Operation in the TV Bands," IEEE, New York, 2015.

[9] IEEE Computer Society, "IEEE 802.11af. Part 11: Wireless LAN Medium Access Control (MAC) and Physical Layer (PHY) Specifications. Amendment 5: Television White Spaces (TVWS) Operation.," IEEE, New York, US, 2013.

[10] V. Popescu, M. Fadda, M. Murroni, J. Morgade and P. Angueira, "CoChannel and Adjacent Channel Interference and Protection Issues for DVB-T2 and IEEE 802.22 WRAN Operation," IEEE TRANSACTIONS ON BROADCASTING, vol. 60, no. 4, pp. 693-700, 2014
[11] A. B. Flores, R. E. Guerra, E. W. Knightly, P. Ecclesine and S. Pandey, "IEEE 802.11af: A Standard for TV White Space Spectrum Sharing," IEEE Communications Magazine, vol. 51, no. 10, pp. 92-100, 2013.

[12] M. Fadda, M. Murroni and V. Popescu, "Interference Issues for VANET Communications in the TVWS in Urban Environments," IEEE TRANSACTIONS ON VEHICULAR TECHNOLOGY, vol. 65, no. 7, pp. 4952-4958, 2016.

[13] Dynamic Spectrum Alliance, "Worldwide Commercial Deployments, Pilots, and Trials," Dynamic Spectrum Alliance Limited, England, UK, 2016.

[14] K. Ishizu, K. Hasegawa, K. Mizutani, H. Sawada, K. Yanagisawa, T. Keat-Beng, T. Matsumura, S. Sasaki, M. Asano, H. Murakami and H. Harada, "Field Experiment of Long-distance Broadband Communications in TV White Space Using IEEE 802.22 and IEEE 802.11af," 17th International Symposium on Wireless Personal Multimedia Communications (WPMC2014), pp. 468-473, 2014.

[15] J. Mack and J. Cartmell, "Field Trial Results for a Wi-Fi Based Spectrum," IEEE Long Island Systems, Applications and Technology (LISAT) Conference, pp. 1-6, 2014.

[16] K.-M. Kang, J. C. Park, S.-I. Cho and B. J. Jeong, "Deployment and Coverage of Cognitive Radio Networks in TV White Space," IEEE Communications Magazine, pp. 88-94, 2012.

[17] L. Simic, M. Petrova and P. Mahonen, "Wi-Fi, but not on Steroids: Performance Analysis of a Wi-Fi-like Network Operating in TVWS under Realistic Conditions," IEEE ICC Cognitive Radio and Networks Symposium, pp. 1533-1538, 2012.

[18] R. Almesaeed, N. F. Abdullah, A. Doufexi and A. R. Nix, "A Throughput Study Of White-Fi Networks in Rural Environment Under Realistic Conditions and Mobility," 2015 IEEE 81st Vehicular Technology Conference (VTC Spring), pp. 1-5, 2015.

[19] M. Fadda, V. Popescu, M. Murroni, P. Angueira and J. Morgade, "On the Feasibility of Unlicensed Communications in the TV White Space: Field Measurements in the UHF Band," International Journal of Digital Multimedia Broadcasting, 2015.

[20] O. Holland, H. Kokkinen, S. Wong, V. Friderikos, A. Raman, M. Dohler and M. Lema, "Changing availability of TV white space in the UK," Electronics Letters, vol. 52, no. 15, pp. 1349-1351, 2016.

[21] M. Deruyck, E. Tanghe, W. Joseph and L. Martens, "Modelling and Optimization of power consumption in wireless access networks," Computer Communications, vol. 24, pp. 2036-2046, 2011.

[22] M. Deruyck, W. Joseph, B. Lannoo, D. Colle and L. Martens, "Designing Energy-Efficient Wireless Access Networks: LTE and LTEAdvanced," IEEE Internet Computing, vol. 17, no. 5, pp. 39-45, 2013.

[23] M. Deruyck, E. Tanghe, D. Plets, L. Martens and W. Joseph, "LTE wireless access networks towards power consumption and electromagnetic exposure of human beings," Computer Networks, no. 94, pp. 29-40, 2016.

[24] A. Arbi and T. O'Farrell, "A comparative Study of Energy Efficiency Between MIMO and SISO based LTE RANs," 2015 IEEE International Conference on Communications (ICC), pp. 43-48, 2015.

[25] G. Auer, V. Giannini, C. Desset, I. Godor, P. Skillermark, M. Olsson and D. Sabela, "How much energy is needed to run a wireless network?," IEEE Wireless Communications, vol. 18, no. 5, pp. 40-49, 2011.

[26] M. Zennaro, E. Pietrosemoli and A. Sathiaseelan, "Architecting a Low Cost Television White Space Network For Developing Regions," Fifth ACM Symposium on Computing for Development, pp. 113-114, 2014.

[27] M. Deruyck, J. Wyckmans, L. Martens and W. Joseph, "Emergency AdHoc Networks by Using Drone Mounted Base Stations for a Disaster Scenario," IEEE 12th International Conference on Wireless and Mobile Computing, Networking and Communications (WiMob), pp. 1-7, 2016.

[28] ETSI, LTE: Base Station (BS) radio transmission and reception (3GPP TS 36.104 version 9.4.0 Release 9), France, 2009.

[29] S. Saunders, Antennas and Propagation for Wireless Communication Systems, 2nd Edition ed., England: Wiley, 2007.

[30] ETSI, "White Space Devices (WSD); Wireless Access Systems operating in the $470 \mathrm{MHz}$ to $790 \mathrm{MHz}$ TV broadcast band," France, 2014. 
[31] MINCOM, "Reglamento para el Servicio de radiodifucsión de Television Digital en las Bandas de VHF y UHF," Gaseta Oficial Cuba, Havana, 2016.

[32] ETSI, "Physical layer aspects for evolved Universal Terrestrial Radio Access (UTRA)," France, 2006.

[33] V. Popescu, M. Fadda, M. Murroni and D. Giusto, "Coexistence Issues for IEEE 802.22 WRAN and DVB-T2 Networks," IEEE BMSB, 2016.

[34] P. Piotrowski, "DVB-T Transmitters in Belgium," SAT Broadcast, [Online]. Available: http://www.satbroadcasts.com/DVBT_transmitters_in_Belgium.html. [Accessed 20 January 2017].

[35] S. Yuan, L. Li and C. Chigan, "A Selfishness-aware Coexistence Scheme for 802.22 and 802.11af Networks," IEEE Wireless Communications and Networking Conference (WCNC), pp. 194-199, 2015.

[36] Carlson Wireless, "Gen3 RuralConnect: TV White Space System," California, 2016.

[37] ETSI, LTE: Radio Frequency (RF) requirements for LTE (3GPP TS 36.104 version 9.4.0 Release 9), France, 2010.

[38] D. Plets, W. Joseph, E. Tanghe, L. Verloock and L. Martens, "Analysis of propagation of actual DVB-H signal in a suburban environment," IEEE Antennas-and-Propagation-Society International Symposium, Vols. 1-12, pp. 1839-1842, 2007.

[39] P. Angueira, M. Velez, D. d. 1. Vega, A. Arrinda and J. L. Ordiales, "Fading Caused by Moving Vehicles near the Receiver on DTV (COFDM) $8 \mathrm{MHz}$ Signals," IEEE Communications Letters, vol. 6, no. 6, pp. 250-252, 2002.

[40] D. Plets, W. Joseph, L. Verloock, L. Martens, H. Gauderis and E. Deventer, "Extensive Penetration Loss Measurements and Models for Different Building Types for DVB-H in the UHF Band," IEEE Transactions on Broadcasting , vol. 55, no. 2, pp. 213-222, 2009.

[41] ITU-R, "Recommendation ITU-R P.1546-5: Method for point-to-area predictions for terrestrial services in the frequency range $30 \mathrm{MHz}$ to 3000 MHz," ITU, Geneva, 2013.

[42] ITU-R, "Recommendation ITU-R P.1812: A path-specific propagation prediction method for point-to-area terrestrial services in the VHF and UHF bands," ITU, Geneva, 2015

[43] A. F. Molisch, Wireless Communications, John Wiley \& Sons, 2011.

[44] M. Deruyck, W. Joseph, E. Tanghe and L. Martens, "Reducing the power consumption in LTE-Advanced wireless access networks by a capacity based deployment tool," Radio Science, no. 49, pp. 777-787, 2014.

[45] B. Mikkelsen, "Challenges and key technologies for coherent metro 100G transceivers," Light Waves, 2012. [Online]. Available: http://www.lightwaveonline.com/articles/print/volume-29/issue6/feature/challenges-and-key-technologies-for-coherent-metro-100gtransceivers.html.

[46] PLANET Technology Corporation, "IGS-624HPT: Industrial 4-Port 10/100/1000T 802.3at PoE," Taiwan, 2013.

[47] N. Zhang and B. Brodersen, "The Cost of Flexibility in Systems on a Chip Design for Signal Processing Applications," Berkeley Wireless Group, California, 2002.

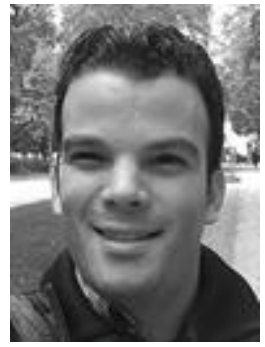

Rodney Martinez Alonso was born in 1987 in Havana, Cuba. In 2010, he obtained a B.Sc. degree in Telecommunications and Electronics Engineering and a M.Sc. degree on Digital Systems (2015) from the Higher Polytechnic Institute CUJAE, Havana, Cuba. Since 2010, he is a fellow researcher at LACETEL, R\&D Telecommunications Institute. He also has collaborated on DTV engineering projects with HAIER and KONKA (China). Currently, he is a PhD student at WiCa group (Department of Information Technology - INTEC, Ghent University).

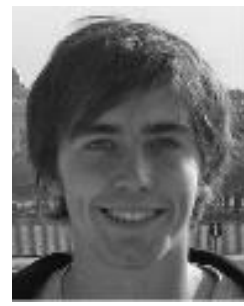

David Plets was born in 1983 in Belgium. $\mathrm{He}$ received the Master degree and $\mathrm{Ph}$. D. degree in 2006 and 2011 respectively. Currently he is member of IMEC WAVES group (Department of Information Technology - INTEC, Ghent University). His current research interests include low-exposure wireless indoor network planning, cognitive networks, WiFi QoS optimization, and localization algorithms.

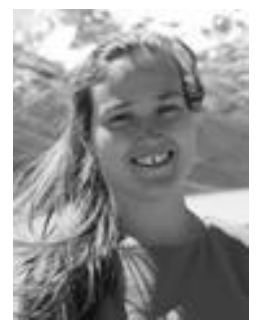

Margot Deruyck Margot Deruyck was born in Kortrijk, Belgium, on July 14, 1985. She received the M. Sc. degree in Computer Science Engineering and the Ph. D. degree from Ghent University, Ghent, Belgium, in 2009 and 2015, respectively. From September 2009 to January 2015, she was a Research Assistant with Ghent University - IMEC - WAVES (Wireless, Acoustics, Environment \& Expert Systems - Department of Information Technology). Her scientific work is focused on green wireless access networks with minimal power consumption and minimal exposure from human beings. This work led to the Ph.D. degree. Since January 2015, she has been a Postdoctoral Researcher at the same institution where she continues her work in green wireless access network. Since October 2016, she is a Post-Doctoral Fellow of the FWO-V (Research Foundation - Flanders). 


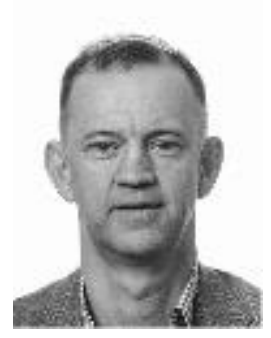

Luc Martens received the M.Sc. degree in electrical engineering from the Ghent University, Belgium in July 1986. From September 1986 to December 1990 he was a research assistant at the Department of Information Technology (INTEC) of the same university. During this period, his scientific work was focused on the physical aspects of hyperthermic cancer therapy. His research work dealt with electromagnetic and thermal modelling and with the development of measurement systems for that application. This work led to the Ph.D. degree in December 1990. Since 1991, he manages the wireless and cable research group at INTEC. This group is since 2004 part of the iMinds institute and since April 1993 he is Professor at Ghent University. His experience and current interests are in modelling and measurement of electromagnetic channels, of electromagnetic exposure e.g. around telecommunication networks and systems such as cellular base station antennas, and of energy consumption in wireless networks. He is author or co-author of more than 300 publications in the domain of electromagnetic channel predictions, dosimetry, exposure systems and health and wireless communications.

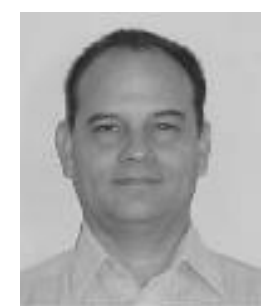

Glauco Guillen Nieto was born in 1961 in Havana, Cuba. In 1985, he obtained a B.Sc. degree in Radiocommunications and Broadcasting Engineering and a $\mathrm{PhD}$. degree (1989) from the Electrotechnical Institute of Communication "A. S. Popov", Odessa, Ukraine. He is currently a senior researcher at LACETEL and elected member of the Cuban Academy of Science (20122018). From 2012, he is a "Series A" advisor of the local network operators. He also has collaborated in different projects with Finline Technology (Canada), DTVNEL (DTV National Engineering Lab - Beijing), HAIER and KONKA (China).

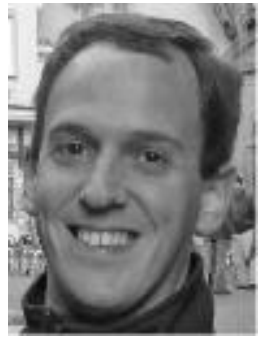

Wout Joseph was born in Ostend, Belgium on October 21, 1977. He received the M. Sc. degree in electrical engineering from Ghent University (Belgium), in July 2000. From September 2000 to March 2005 he was a research assistant at the Department of Information Technology (INTEC) of the same university. During this period, his scientific work was focused on electromagnetic exposure assessment. His research work dealt with measuring and modelling of electromagnetic fields around base stations for mobile communications related to the health effects of the exposure to electromagnetic radiation. This work led to a $\mathrm{Ph}$. D. degree in March 2005. Since April 2005, he is postdoctoral researcher for iMinds-UGent/INTEC. From October 2007 to October 2013, he was a Post-Doctoral Fellow of the FWO-V (Research Foundation - Flanders). Since October 2009, he is professor in the domain of Experimental Characterization of wireless communication systems. His professional interests are electromagnetic field exposure assessment, in-body electromagnetic field modelling, electromagnetic medical applications, propagation for wireless communication systems, antennas and calibration. Furthermore, he specializes in wireless performance analysis and Quality of Experience. 